\title{
MENINA ATREVIDA E MENINA TODATEEN: AS REPRESENTAÇÕES SOCIAIS DAS ADOLESCENTES NOS DISCURSOS DAS REVISTAS DO PÚBLICO TEEN
}

\author{
ATREVIDA GIRL AND TODATEEN GIRL: TEEN SOCLAL REPRESENTATIONS IN \\ TEEN PUBLIC MAGAZINE SPEECHES
}

ANA RAQUEL DA SILVA COSTA ${ }^{1}$

\begin{abstract}
Resumo: O presente artigo apresenta uma análise das revistas mensais Atrevida e Todateen, destinadas para o público feminino adolescente, buscando compreender as representações sociais do público teen através dos discursos desses meios de comunicação. Para constituir os observáveis de pesquisa, foram selecionadas uma edição de cada impresso do mesmo mês e ano de publicação e para fins de recorte a análise aqui feita será a partir das capas de cada um dos impressos. Para tanto tem-se como base teórica autores como Hall (2016), Jodelet (1993), Moscovici (2012), Scalzo (2003), entre outros. Diante do exposto, se compreende que as revistas adolescentes vendem representações de vida para seu público, apresentando as formas de como agir, ser, comprar e consumir.
\end{abstract}

Palavras-chave: Representações Sociais; Adolescentes; Revistas Femininas; Discurso

Abstract: This article presents an analysis of the monthly journals Atrevida and Todateen, intended for the adolescent female audience, seeking to understand the social representations of the adolescent audience through the discourses of these media. To constitute the research observables, one edition of each form of the same month and year of publication was selected and for the purpose of clipping the analysis made here will be from the covers of each form. For such, we have as theoretical base authors such as Hall (2016), Jodelet (1993), Moscovici (2012), Scalzo (2003), among others. Given the above, it is understood that adolescent magazines sell life representations to their audience, presenting the ways of acting, being, buying and consuming.

Keywords: Social Representations; Teenagers; Women's Magazines; Speech

\section{INTRODUÇÃO}

O presente artigo apresenta uma análise de revistas mensais Atrevida e Todateen, destinadas para o público feminino adolescente, buscando compreender a representação social do público teen através dos discursos desse meio de comunicação. Para constituir os observáveis de pesquisa, foram selecionadas uma edição de cada impresso do mesmo mês e

\footnotetext{
${ }^{1}$ Mestranda em Comunicação no PPGCOM - Programa de Pós-Graduação em Comunicação da Universidade Federal do Piauí (UFP). Graduada em Comunicação Social com Habilitação em Jornalismo pela Universidade Federal do Piauí (UFPI).
} 
ano de publicação, podendo ser feita também a comparação de abordagens feitas por ambas as mídias.

A Revista Atrevida tem como público-alvo adolescentes de 14 a 17 anos, sendo veiculada pela Editora Escala. Com data inicial de circulação na primeira semana de cada mês, a revista se apresenta como a melhor amiga da sua espectadora que traz soluções para diversas questões que possam vir a surgir. Partindo desse ponto, tem-se a Revista Todateen, que se apresenta para o público alvo de meninas com idade entre 13 e 17 anos. Com data inicial de circulação no quinto dia útil do mês, a revista também aborda uma diversidade de assuntos que podem fazer parte do cotidiano do seu público principal.

As revistas selecionadas compreendem as edições do mês de fevereiro de 2017, considerado como o período de volta às aulas nas escolas e um dos principais assuntos abordados nas revistas no referido espaço de tempo. Compreendendo todos esses fatores, tem-se o fato de considerar a segmentação de público e o aprofundamento dos temas abordados. Conforme relata Scalzo (2003), as revistas podem ser consideradas os meios termos entre a profundidade oferecida por um livro e a característica de relatos mais diretos no jornal. Tem-se então uma quantidade bastante expressiva de conteúdos que se podem analisar, partindo disso a análise aqui feita será a partir das capas de cada um dos impressos.

Para chegar em tais objetivos busca-se compreender o conceito de Representação Social nas perspectivas de Moscovici (2012) e Jodelet (1993), tendo em vista também as definições aliadas à cultura feitas por Hall (2016). Além disso, o presente artigo tem como base teórica autores que trazem o discurso e sua análise à tona, tendo em vista a necessidade de se compreender o que realmente falam os meios de comunicação. Diante disso, o corpus de pesquisa será analisado à luz da metodologia da Análise de Discurso.

Diante do questionamento sobre como as adolescentes são representadas no discurso das duas revistas, faz-se a discussão teórica sobre os temas que dão suporte à análise, discutindo também os procedimentos metodológicos adotados. Parte-se então para a descrição do observável selecionado, chegando então a análise do material compreendendo todas as formas de alcançar o discurso para além das chamadas de reportagens na capa.

\section{CARACTERIZANDO O MEIO: AS REVISTAS FEMININAS}

Na produção de conteúdo dentro dos meios de comunicação a segmentação tem alcançado grupos cada vez mais específicos de público-alvo. Nesse contexto, tem-se as revistas impressas femininas para adolescentes com uma variedade de matérias sobre variados assuntos que acreditam ser de interesse de seu público específico. 
Segundo Scalzo (2003) o mercado de revistas femininas começa a surgir em meados do século XIX e na primeira metade do século XX, com o intuito de trazer novidades sobre a moda vindas da Europa, juntamente com conselhos culinários, artigos, anedotas, notícias e ilustrações. A segmentação editorial dentro das revistas enquanto ferramenta mercadológica começa a dar os seus primeiros passos no final da década de 1950 e no decorrer da década de 1960 quando começam a acompanhar o desenvolvimento industrial e ser vistas como "bons meios de veículos para a publicidade" (SCALZO, 2003, p.33).

Em relação à segmentação que começa a ser abordada, Abiahy (2000) defende que a segmentação pode ser considerada como a substituição da massificação pela personalização. Ou seja, a lógica da especialização de conteúdo tem a tendência de afunilar as informações e especializar um mercado. Dessa forma, o produto jornalístico tende a ser mais proveitoso tanto para o público quanto para os detentores das empresas jornalísticas, que podem focar em um tipo de produção ao invés de lançar informações "na sorte", com o intuito de acertar todos. Já para o público, fica mais fácil buscar as informações segundo seu perfil, onde é encaminhado para o tipo de informação que rodeia seu "universo".

Nessa mesma perspectiva, Scalzo (2003) relata que a forma de fazer jornalístico encontrado nas revistas possui uma capacidade de servir como instrumento de afirmação de identidade de grupos que possuem interesses específicos, o que a autora chama de "carteirinha de acesso" às informações que atendem essa demanda. Dessa forma, as revistas são mais reafirmadas como um meio de comunicação que possui a capacidade de se aproximar de grupos mais específicos. Como afirma Abiahy (2000) a segmentação chega como uma resposta para um mercado como necessidades de conteúdos mais voltados para seus interesses, não sendo considerada uma individualização, mas a agrupação de grupos que produzem uma demanda de mercado específica.

Além disso, o fato das revistas fazerem parte de segmentos editoriais contribui para manter sua proposta de aprofundamento que seria o meio termo entre o jornal e o livro, tendo então que se direcionar para um tipo de público para não abarcar todos os tipos de conteúdo. Conforme discute Scalzo (2003) o meio de comunicação que busca cobrir tudo enquanto revista acaba não cobrindo nada, fugindo assim do objetivo de profundidade da mídia impressa. Abiahy (2000) também concorda com essa afirmação na sua perspectiva de que o "crescimento dessas produções revela que a proposta de informação dirigida a interesses específicos está de acordo com a necessidade do público receptor. " (Idem, p.16). É um tipo de mídia que tem interesse em se aproximar do estilo de vida do leitor e de sua 
linguagem, podendo assim introduzir mais facilmente seus conteúdos e interesses mercadológicos.

Dentro desse contexto do surgimento das revistas femininas se torna importante ressaltar que a maioria dessas publicações eram produzidas por homens pois. Conforme aponta Scalzo (2003) existiam publicações feitas de mulheres para mulheres que ultrapassavam os assuntos apontados acima e traziam uma problematização sobre suas condições de vida e direitos, mas não duravam muito. Havia então nesse período uma prevalência de conteúdos produzidos por homens que abordavam assuntos mais restritivos sobre as mulheres contribuindo assim na construção social de um modelo de vida feminino.

As fotonovelas que surgem na década de 1950, ainda não traziam nenhum aprofundamento em questões que provocassem reflexão social, sendo destinadas ao lazer. De acordo com Scalzo (2003), só quando as mulheres começam a exigir a presença de algo diferente que as atendesse enquanto público consumidor que surgem produções com algumas mudanças em suas abordagens, a exemplo da revista Cláudia que se propôs a acompanhar o novo ritmo das mulheres e o crescente mercado da indústria dos eletrodomésticos. Ainda que trazendo assuntos antes não apontados, como consultas jurídicas, saúde e sexo, as publicações ainda continuam a reforçar o papel da mulher como "do lar" ao abordar questões como orçamento doméstico e a apropriação de eletrodomésticos para o uso diário em casa.

Assuntos antes intocáveis, como a solidão, o machismo, o trabalho, seus problemas sexuais, etc. passam a ser abordados a partir do ingresso da mulher no mercado de trabalho, conforme relata Scalzo (2003). Ainda que de forma pequena, algumas abordagens sobre a mulher a classificam além da dona de casa, passando a ter uma identidade complexa. O mercado de revistas continua tentando acompanhar o desenvolvimento das mulheres e seus interesses, produzindo inclusive segmentações dentro do público feminino, como o observável dessa pesquisa, que se destina a adolescentes.

\section{REPRESENTAÇÕES SOCIAIS E PRODUÇÃO DE SENTIDOS NA MÍDIA}

O conceito de Representações Sociais é apresentado por Moscovici em 1961 através de seu estudo intitulado "La Psychanalyse: Son image et son public". Tal formulação parte do conceito de Representações Coletivas apresentado por Émile Durkheim. Em meio a uma proposta de separação definitiva no campo da Psicologia social entre Sociologia (Representações Coletivas) e Psicologia (Representações Individuais), Moscovici apresenta, 
através de seu trabalho, o argumento de que uma análise de cunho social também necessita de uma introdução de conceitos de psicologia.

De acordo com Moscovici (2012) as representações sociais possuem duas funções na sociedade que delimitam até que ponto elas intervêm na atividade cognitiva do indivíduo ou são independentes dela. A primeira função diz respeito a convencionalização do objeto de representação, lhe atribuindo sentidos que o localizam dentro de uma determinada categoria, começando a ser construído como um modelo que passa a ser inserido e compartilhado entre os grupos sociais. A segunda função, denominada de prescritiva, seria uma força exterior aos indivíduos proveniente de uma estrutura que construída antes que pudessem pensar, como uma tradição que decreta o que e como deve ser pensado.

Com base no conceito proposto por Moscovici e suas reflexões acerca de representações, Jodelet (1993) coloca que as representações surgem da incerteza que os indivíduos têm de algo e da falta de informação sobre colocações que circulam na sociedade. Dessa forma, segundo a autora, essas representações vão se encaixando em quadros préexistentes, tentando preencher os vácuos das ausências de significados e na atribuição de significados pelos indivíduos.

Segundo Moscovici (2012), a função de todas representações sociais se trata de tornar o não-familiar em familiar, pois aquilo que não é conhecido incomoda, causando dentro do ser humano a necessidade de encaixar o conceito em uma categoria ou criar uma própria, em concordância com as reflexões feitas por Jodelet (Idem). A dinâmica de familiarização que Moscovici (2012) apresenta consiste, de forma simplificada em perceber e compreender objetos, pessoas e acontecimentos através de uma relação com encontros que já aconteceram anteriormente. Ou seja, o novo e não familiar recebe uma classificação de acordo com os parâmetros familiar já existentes no imaginário humano que mais se aproxima do que não é familiar.

Segundo afirma Jodelet (1993), apesar de ser diferente do conhecimento científico, a produção de representações é tão legítima como tal por ser um agente importante na sociedade com capacidade de esclarecer processos de cognição e interações sociais. Ao colocar a forma como foi construída a representação social da AIDS, a autora percebe uma lógica de construção da representação que pode ser empregada como uma função cognitiva importante dela. Nesse caso, há uma representação moral e física, onde as duas se constroem para acolher o novo, o não familiar.

Estas se instalam sobre valores variáveis segundo os grupos sociais dos quais retiram suas significações, bem como os saberes anteriores 
reativados por uma situação social particular - e veremos que se trata de um processo central na elaboração representativa. São ligadas a sistemas de pensamentos mais amplos, ideológicos ou culturais, a um estado dos conhecimentos científicos, bem como a condição social e à esfera da experiência privada e a afetiva do indivíduo. (JODELET, 1993, p. 4)

Dentro dessa perspectiva da autora, Moscovici (2012) apresenta o processo de ancoragem e objetivação das representações sociais como processos do pensamento que tem sua base na memória e em conclusões previamente existentes. A ancoragem é descrita pelo autor como um mecanismo que procura ancorar o estranho em imagens e categorias comum aos indivíduos, colocando-as em um contexto familiar. O segundo mecanismo descrito se trata da objetivação, um processo responsável por transformar o que é considerado abstrato em algo considerado mais concreto, associando o que está na mente com elementos existentes no mundo físico. É uma transferência das ideias e do pensamento para a realidade. Tais reflexões servem para compreender que os sentidos são produzidos e convencionalizados, inclusive pela mídia.

Jodelet (1993) afirma que as representações são reconhecidas como sistemas de interpretação que regem as relações sociais orientando e organizando condutas e a comunicação social. Ou seja, a sociedade está atravessada por representações que regulam relações enquanto também é responsável por construí-las. "Igualmente intervêm em processos tão variados quanto a difusão e a assimilação dos conhecimentos, no desenvolvimento individual e coletivo, na definição das identidades pessoais e sociais, na expressão dos grupos e nas transformações sociais. ” (Idem, 1993, p. 5)

Partindo de uma reflexão sobre como as representações regem as relações sociais, trazemos Hall (2016) contribuindo com sua colocação de que a representação tem capacidade de conectar sentindo e linguagem à uma cultura, constituindo parte importante da produção de significados. Tal afirmação vai de encontro a afirmação de Moscovici (2012) apontando que uma vez que seja difundido, o conceito passa a fazer parte da cadeia de significados cumprindo seu papel na sociedade.

Ao considerar as representações sociais como maneiras de organizar a sociedades de diferentes formas, Hall (2016) vai de encontro com o conceito de previamente formulado por Moscovici para rebater o caráter estático das representações coletivas. Segundo o autor, o sentido não pode ser fixado ou estático pois se trata de fruto de convenções sociais, culturais e linguísticas, não havendo um sentido final ou absoluto. Levando em consideração tal característica, os sentidos mudariam de uma cultura para outra e até de um período para outro. 
Trazendo as funções de convencionalização e prescrição das representações sociais é possível observar sua atuação nesses processos de construção dos sujeitos e das identidades perante a cultura. Aquilo que um indivíduo apresenta não se trata de conhecimento aleatório ou próprio de sua constituição biológica.

\footnotetext{
Nossas afirmações são baseadas em proposições e premissas das quais nós não temos consciência, mas que são, por assim dizer, conduzidas na corrente sanguínea de nossa linguagem. Tudo que dizemos tem um "antes" e um "depois" - uma "margem" na qual outras pessoas podem escrever (HALL, 2006, p. 41)
}

De acordo com Moscovici (2012) todas as interações humanas pressupõem representações em sua composição e que é isso que as caracteriza. Para reforçar o caráter de cultura compartilhada, pode-se trazer a afirmação de Moscovici (2012) acerca da criação de representações sociais não serem criadas por um indivíduo isoladamente. É necessária essa interação e troca. A construção de sentidos é atravessada pelas representações ao ligar sentidos e linguagem a cultura em uma construção constante que se modifica conforme as convenções e prescrições se modifiquem. Dessa forma, deve-se apontar como a mídia atua nesse processo para compreender como as duas mídias impressas estudadas atuam como produtora de representações sociais através do discurso.

\section{REPRESENTAÇÕES SOCIAIS NO DISCURSO DAS REVISTAS TEENS}

Diante de todo o aporte teórico apresentado sobre representações sociais e revistas, busca-se então na análise de discurso o aparato teórico e metodológico ao qual se chegará na análise das revistas selecionadas. Ao buscar essas respostas busca-se compreender as produções discursivas que se apresentam naquela capa e quais estão "por trás" dessa materialização.

Tendo em vista a segmentação do mercado editorial de revistas como uma estratégia de mercado para alcançar diferentes públicos, ao falar sobre como se dá o discurso das mídias, o autor Charaudeau (2006) dialoga com essa reflexão ao afirmar que uma visão econômica interfere de forma direta sobre as questões de produção de conteúdo. Segundo o autor, a análise estaria ligada tanto à compreensão da produção como da recepção, uma vez que deve se observar a troca entre os dois pontos e não os isolar como independentes.

Em congruência com a reflexão de Moscovici (2012) onde as representações sociais não são estáticas e estão sempre em constante ajustes de sentidos, Charaudeau (2006) declara que o discurso da mídia ao relatar um acontecimento constrói uma representação que não se trata do real. Dessa forma, precisamos entender que as representações das coisas não seria o 
real em sua gênese, mas algo construído discursivamente em sociedade. Como relata Moscovici (2012), o indivíduo não consegue lidar com o não familiar e busca categorizações para que passe a ser familiar. Isso, então, que acontece com as mídias que estão buscando sempre categorizar fatos em categorias apresentando para o público representações sociais que possam vir a ser difundidas.

Importante perceber que a instância da recepção referente ao público não se trata de indivíduos que recebem essas representações e as absorve tal como a mídia impõe. Embora o foco deste artigo não seja a recepção, se torna importante esclarecer essa questão para que esteja claro que há representações que são recebidas de diferentes formas pelos sujeitos. Segundo Charaudeau (2006) esse público interpreta essas informações cada um de acordo com suas condições interpretativas. Além desses dois aspectos, se torna importante compreender o produto midiático que pode ser compreendido como a materialização dos discursos.

Ao partir para a compreensão de discursos das mídias, Charaudeau (2006) contribui com essas colocações ao dizer que a efetivação da produção de sentidos só se torna possível através da linguagem dentro de uma situação de troca social. Ou seja, "a coisa" não nasce e diz qual o seu sentido, ele se constrói na interação social e na negociação entre os indivíduos que vão acordar qual sentido geral terá, mesmo abrindo margem para interpretações a partir disso. Devido a isso, o autor coloca que os discursos se tratam de representações de relações sociais antes de serem a representação do mundo real, que seria visto através das lentes que surgem da negociação de sentidos entre indivíduos.

Ao compreender que os significados não vêm com o surgimento das coisas, Charaudeau (2006) aponta que da articulação entre o poder e o saber nasce o discurso. Tal afirmação abre margem para refletirmos o porquê de um veículo analisado escolher um enunciado em detrimento de outro, assim como o uso de adjetivos e a escolha das pautas abordadas. Nessa perspectiva o autor declara que a linguagem e as palavras não seriam transparentes em si mesmas.

Partindo para um outro ponto, ao resgatar a reflexão de Moscovici (2012) sobre como as representações sociais são construídas coletivamente, Charaudeau (2006) enfatiza que os indivíduos criam um jogo de regulação das práticas sociais. Através da troca feita, sentidos são produzidos, representações são construídas e assim o discurso vai se materializando através da linguagem. De acordo com Charaudeau (2006) quando as mídias representam essas práticas através de seu discurso, abre margem para o estabelecimento de convenções, fortalecendo ou estabelecendo-as. 
Ao discorrer como se dá a lógica de funcionamento das revistas impressas, em especial as destinadas ao segmento feminino adolescente, se acordo com a informação de Charaudeau (2006) sobre a importância de compreender a mídia em que se materializa o discurso como um dispositivo que tem poder de influência sobre a informação e conteúdo repassados. Cada dispositivo tem características próprias que acabam influenciado na forma como se dá a materialização do discurso, inclusive na forma como é pensado antes de se imprimir, a exemplo das características apresentadas sobre as revistas enquanto meios de comunicação.

Diante dessa discussão sobre discurso e representação social, deve-se compreender as mídias manipulam a informação, como aponta Charaudeau (2006), essa manipulação nem sempre é intencional. Se trata dos recortes, das imagens, da linha editorial, do espaço e tempo que se tem disponível, etc. $\mathrm{O}$ autor aponta que, embora manipulem informações, as mídias são importantes para a democracia. Quando as mídias entram na equação da troca social entre os indivíduos para determinar os sentidos haveria ali uma "deformação" do real em sua materialização, podendo então incidir sobre as representações que se tem na sociedade.

\section{MENINA ATREVIDA E MENINA TODATEEN: AS REPRESENTAÇÕES SOCIAIS DAS ADOLESCENTES NAS REVISTAS}

As revistas selecionadas compreendem as edições de fevereiro de 2017, considerado como o período de volta às aulas das escolas por ambas as edições. A capa da revista Atrevida (Figura 01) traz chamadas de matérias que são consideradas mais importantes dentro de suas páginas. Nesta edição, o impresso traz como figura principal a cantora e atriz Larissa Manoela, onde as informações se alocam em torno dela, transmitindo a informação de que o assunto principal seria a matéria feita com ela.

Figura 01 - Capa da Revista Atrevida (fevereiro de 2017) 


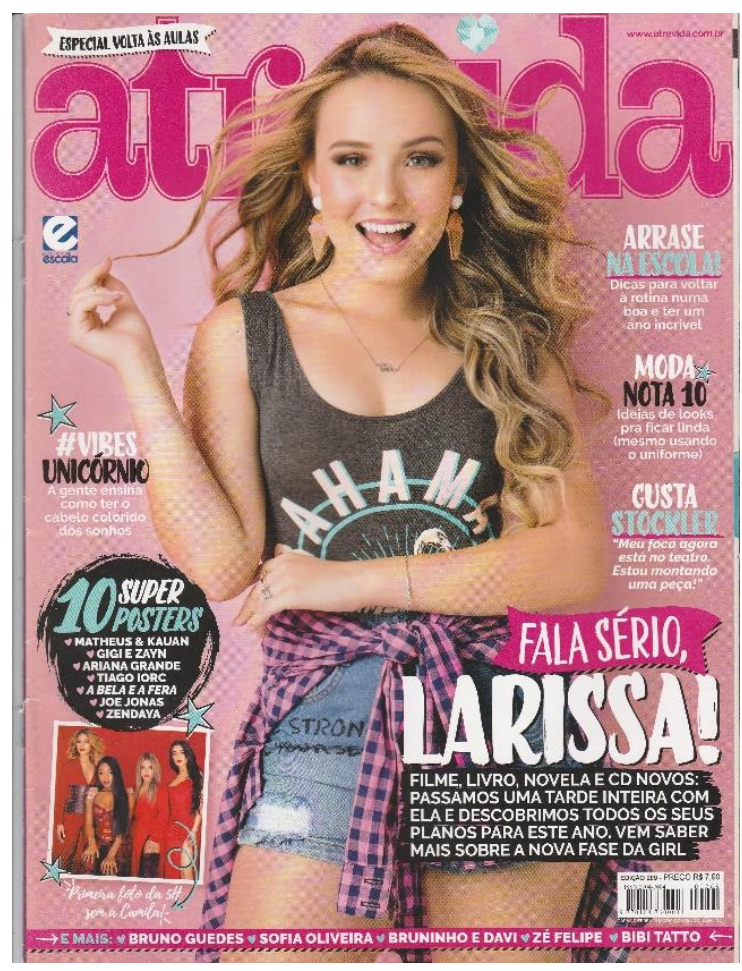

Fonte: Revista Atrevida, ano 22, edição 269

O uso de celebridades na capa, pode ser considerado como uma estratégia de mercado para chamar o público adolescente. As revistas se dedicam a discorrer não apenas sobre a vida das meninas, mas trazem também uma grande quantidade de conteúdo sobre personalidades famosas. Diante isso, já se começa a perceber que a revista entende a adolescente como um indivíduo que tem interesse na vida dos ídolos teens, onde a revista se coloca na posição de fala de entender as necessidades de informação de todas as adolescentes.

O nome da revista se apresenta na parte de cima em cor que combina com o cenário da foto e as demais chamadas da matéria. É percebido também que as cores e fontes das demais chamadas combinam com os tons da roupa usada pela celebridade, reforçando a ideia de que ela seria a "estrela" daquela edição e que se trata de um assunto de suma importância para a adolescente. A chamada "Fala sério, Larissa!", além de fazer alusão ao filme estrelado pela atriz chamado "Fala sério, mãe!", provoca essa sensação de proximidade com o personagem mediante o uso de linguagem informal. A revista então se propõe a ser como o elo que liga a adolescente ao ídolo, sendo essa ligação representada como uma necessidade na vida do público.

A revista vende para o público teen uma idealização de vida através da vida dos personagens, aborda representações de modelos perfeitos de vida, a exemplo da declaração "Passamos uma tarde inteira com ela e descobrimos todos os seus planos para este ano. Vem 
saber mais sobre essa nova fase da girl' (ATREVIDA, 2017, ed. 269). Temos então uma das representações de ideal de vida adolescente sendo proposto para o consumo desse público. A cada mês a revista apresenta uma figura principal trazendo representações plurais de vidas que valem a pena serem seguidas, em conjunto com os demais personagens que são apresentados na capa e no copo da edição.

Em relação às voltas as aulas, a revista coloca que a edição traz um "Especial volta às aulas" (ATREVIDA, 2017, ed.269) com diversas matérias. Um dos pontos abordados na capa se trata do "ARRASE NA ESCOLA! Dicas para voltar à rotina numa boa e ter um ano incrível", onde se pode perceber o se colocar enquanto manual eficiente para se sair bem na situação. Além de representar em seu conteúdo como a adolescente deve se portar diante do acontecimento, palavras como "ARRASE", buscam reforçar a concepção de que as dicas repassadas são as formas certas de se portar nas voltas aulas, que se propagaria na promessa de caso cumpra as indicações, não só o primeiro dia de aula seria bom, mas todo o ano. A revista também se propõe a apresentar uma "MODA NOTA 10" que, ao fazer alusão às notas da escola, estaria apresentando as representações corretas de formas de se vestir que seriam corretas trazendo "Ideias de looks pra ficar linda (mesmo usando uniforme)" (ATREVIDA, 2017, ed.269). Essa afirmação, também apresenta uma adolescente que não se afeiçoa às roupas que não estejam na moda (como o uniforme escolar) buscando alternativas para se enquadrar nas categorizações das formas certas de ser adolescente.

Ainda em relação à moda e formas de ser, a revista traz uma chamada de matéria “\#vibes unicórnio / A gente ensina como ter o cabelo colorido dos sonhos" (ATREVIDA, 2017, ed.269) como um modo de se apresentar enquanto adolescente. O uso da expressão "vibes" acompanhado de “\#” remete à linguagem em redes sociais onde esse seria o modo de estar naquele determinado momento. Estar dentro desse padrão de comportamento, caberia como uma das características da adolescente atrevida onde a revista quem ensina para que a adolescente possa ter. A expressão "dos sonhos" se revela como se fosse o desejo de todas meninas, concluindo que toda adolescente quer estar na "\#vibes unicórnio".

Em toda capa, essas informações sobre volta às aulas e moda para cabelos, todos os demais conteúdos apresentados na capa se tratam de assuntos relacionados à famosos. Levando em consideração que a capa e as chamadas da matéria devem fisgar a atenção do leitor, ao colocar esta distribuição de conteúdo a revista representa adolescentes que dão bastante valor à vida desses personagens e que eles seriam um modelo de vida a ser seguido. A exemplo da chamada na lateral inferior esquerda que chama o público para o fato da revista trazer a "Primeira foto do 5H sem a Camila!". O 5H em questão se trata de um grupo 
musical de meninas estadunidense, onde uma das participantes deixou a banda em dezembro de 2016. Ver essa imagem se apresenta como um assunto importante para a vida das adolescentes da revista Atrevida.

Em relação à revista Todateen (Figura 02), a capa também traz chamadas de várias matérias que serão abordadas e há também o uso da personalidade famosa, o cantor Shawn Mendes. O nome do impresso se apresenta na parte de cima com a fotografia do artista no meio do espaço e as demais chamadas ao seu redor, sendo ele a figura principal desta edição. Se percebe que há uma categorização das meninas como interessadas na vida de personalidades famosas, uma vez que a maioria dos assuntos abordados também são eles.

\section{Figura 02 - Capa da Revista Todateen (fevereiro de 2017)}

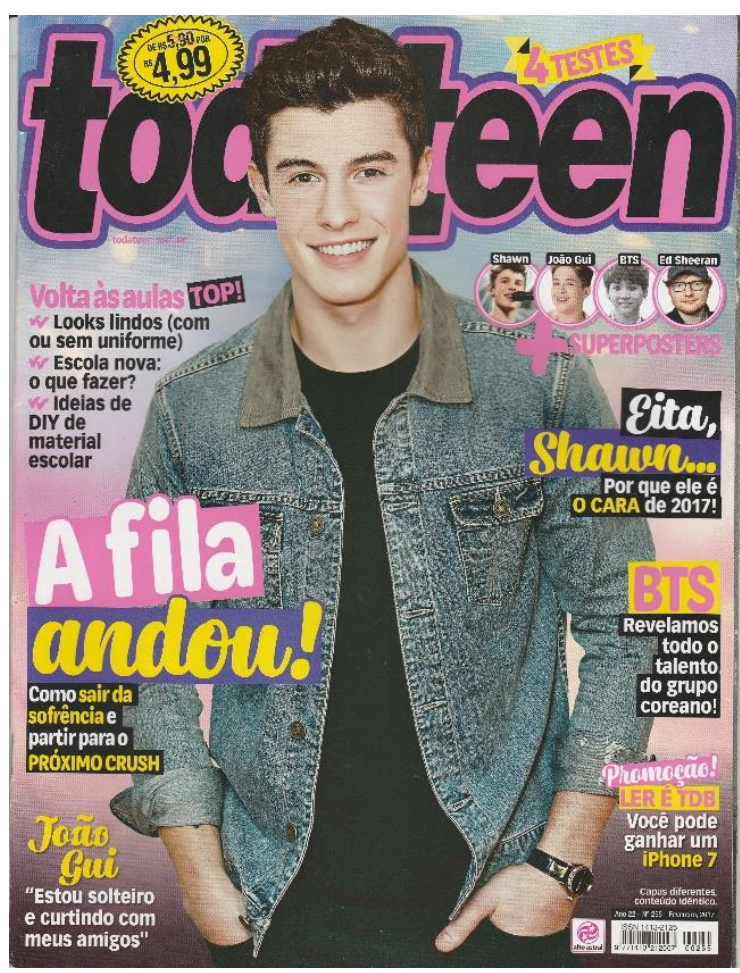

Fonte: Todateen, ano 22, ed.255

A chamada "Eita, Shawn... Por que ele é O CARA de 2017” (TODATEEN, 2017, ed.255) se apresenta bem taxativa como um decreto já estabelecido de que as adolescentes sabem que ele é a figura masculina mais importante do ano. Além da representação do interesse na vida dos famosos por parte dessas meninas, a revista ainda se propõe a apresentar que para o seu público os moldes de menino perfeito que devem considerar se baseiam nas características dessas personalidades.

A edição da revista também traz um conteúdo para a volta às aulas, apresentando que com as dicas da revista esse momento vai ser "TOP! ", representando os comportamentos 
que a adolescente “Top! ” tem que ter. A revista também vende a ideia de meninas que se importam com sua aparência com a matéria "Looks lindos (com ou sem uniforme)", além de um guia de comportamento sobre como agir em situações conflituosas como a mudança de escola. A adolescente da revista Todateen sabe agir da maneira correta para que assim todas as coisas em sua vida deem certo, inclusive fazendo seu próprio material escola através do "Do It Yourself - DIY" (faça você mesmo). Tal arranjo se apresenta mediante a popularização da prática na internet, a revista tem interesse em convencionalizar mediante o interesse do seu público.

O impresso ainda faz uso de representações das formas da linguagem adolescente através da materialização das chamas. Expressões como "Eita"; "Cara"; "DIY”; "Crush"; "sofrência"; "TDB"; "TOP” e "A fila andou", além de serem uma tentativa de se aproximar do leitor, mostram as formas que todas as adolescentes se expressão através da fala. Uma vez que a revista se destine a todo público teen, ainda que não alcance todo ele, compreende que essa é a representação da forma como falam e se entendem.

A matéria "A fila andou! Como sair da sofrência e partir para o PRÓXIMO CRUSH", chama para uma representação social de comportamento em relações amorosas. A adolescente para a Todateen não deve perder seu tempo sofrendo por alguém, mas superar e seguir em frente. Quando a chamada diz para "partir para o próximo" automaticamente anula a possibilidade de que a adolescente feliz pode estar sem ninguém. Se dar um valor alto para a figura do outro, devendo a este a felicidade que a menina busca.

\section{Considerações Finais}

Diante do exposto, se compreende que as revistas adolescentes vendem representações de vida para seu público que, caso seguidas à risca, podem levar para uma vida perfeita. Ao analisar as duas capas, se percebeu que dentro do universo apresentado pelos dois impressos não cabe a adolescente triste ou fora dos padrões de vida apresentados.

Em ambas as revistas, há uma semelhança nos conteúdos reforçando que as representações da adolescência aqui em questão se dão através das trocas sociais. Os dois impressos representam uma linguagem adolescente através das chamadas das matérias como se estivesse conversando com sua leitora. Ao mesmo tempo que alguns assuntos aparecem nas duas, se diferenciam em trazer outros assuntos. As adolescentes representadas em ambas as revistas conversam em alguns pontos, mas se diferem em outros, podendo inclusive ser resultado das duas. 
A vida das adolescentes representadas nesses exemplares gira em torno dos acontecimentos da vida das personalidades famosas, sendo estas apresentadas como modelos de vida que também devem ser seguidos. O manual teen apresenta as representações corretas de como agir, ser, comprar e consumir. $\mathrm{O}$ discurso dessas revistas tem como fundo de pano o consumo material e imaterial.

\section{Referências Bibliográficas}

ABIAHY, A. C. de A. O jornalismo especializado na sociedade da informação.

Monografia de Graduação, Curso de Jornalismo, Universidade Federal da Paraíba/PB, 2000.

ATREVIDA. São Paulo: Escala, n. 269, jan. 2017.

CHARAUDEAU, P. Discurso das mídias. São Paulo: Contexto, 2006.

HALL, S. A identidade cultural na pós-modernidade. TupyKurumin, 2006.

HALL, S. Cultura e representação. PUC-Rio, 2016.

JODELET, D. Representações sociais: um domínio em expansão. Tradução de Tarso Banilha Mazzotti. UFRJ - Faculdade de Educação, 1993.

MOSCOVICI, S. Representações sociais: investigações em psicologia social. In:

Representações sociais: investigações em psicologia social. Vozes, 2012.

SCALZO, M. Jornalismo de revista. Editora contexto, 2003.

TODATEEN. São Paulo: Alto Astral, n. 255, fev. 2017. 